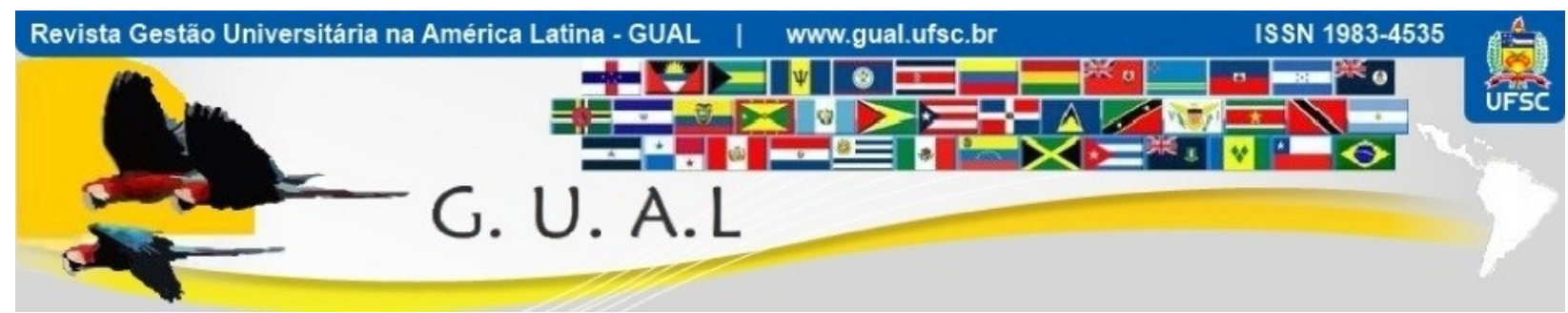

DOI: http://dx.doi.org/10.5007/1983-4535.2018v11n2p198

\title{
O PERFIL DE ALUNOS DO CURSO DE ADMINISTRAÇÃO: UM ESTUDO COM BASE NAS GERAÇÕES X, Y E Z
}

THE PROFILE OF BUSINESS ADMINISTRATION STUDENTS:

A STUDY BASED ON XYZ GENERATIONS

Luisa Bunn Zomer, Bacharel Faculdade CESUSC luisabz@hotmail.com

Aline Regina Santos, Doutora Universidade do Estado de Santa Catarina - UDESC aline.santos@udesc.br

Kelly Cristina de Oliveira Costa, Mestre

Faculdade CESUSC

kelly.costa@cesusc.edu.br

Recebido em 11/dezembro/2017

Aprovado em 12/abril/2018

Artigo apreciado pela modalidade Fast-Track - XX SemeAD

Sistema de Avaliação: Double Blind Review

Esta obra está sob uma Licença Creative Commons Atribuição-Uso. 


\title{
RESUMO
}

A Teoria das Gerações, popularmente conhecida a partir do trabalho de Straus e Howe (1991), fundamenta-se na ideia de que os indivíduos apresentam comportamentos similares em função do período em que nasceram. Tais períodos são marcados por acontecimentos significativos na história e economia de um país, região ou mesmo do mundo. A literatura aponta as Gerações XYZ como os grupos atualmente em destaque, formado por nascidos entre meados da década de 60 até a atualidade. No campo da Administração, as publicações abordam, com frequência, as gerações no contexto do ambiente de trabalho, numa tentativa de compreender o comportamento dos colaboradores. O presente artigo, por sua vez, tem como propósito analisar o perfil dos alunos de Administração de uma instituição de ensino superior privada à luz das gerações XYZ. Para tanto, foi conduzida pesquisa survey com 152 dos 185 discentes regularmente matriculados. Entre os principais resultados encontrados destaca-se o nível baixo a moderado de influência das gerações em algumas situações específicas - o que sinaliza cuidado ao tratar do tema "Geração XYZ". As maiores diferenças observadas são em relação à Geração $X$, comparativamente as demais, revelando um perfil mais comprometido e engajado, no tocante ao comportamento em sala.

Palavras-chave: Gerações XYZ. Perfil Discente. Curso de Administração.

\begin{abstract}
The Theory of Generation, popularly known from the work of Straus and Howe (1991), is based on the idea that individuals have similar behaviors depending on the period in which they were born. Such periods are defined by significant events in the history and economy of a country, region or even the world. The literature points to the XYZ Generations as the currently featured groups, formed by born between the mid-60s to the present. In the field of Administration, publications often approach generations in the context of the work environment in an attempt to understand employee behavior. On the other hand, this research paper aims to analyze the profile of Management students of a private university, comparing the results to the XYZ generations. Therefore, a survey was conducted with 152 of the 185 students enrolled regularly. Among results, is highlighted the low to moderate level of influence of the generations in some specific situations - which signals care when dealing with the theme "Generation XYZ". The greatest differences observed are related to Generation $\mathrm{X}$ comparing the others, revealing a more committed and engaged profile, regarding the student behavior in the class.
\end{abstract}

Keywords: Generations XYZ; Student Profile; Business Administration Course. 


\section{INTRODUÇÃO}

Pode o comportamento humano guardar relações em função da época de nascimento do indivíduo? O estudo das gerações diz que sim. De acordo com esta abordagem, conforme o período em que os indivíduos nasceram e cresceram suas atitudes e comportamentos se apresentam de maneira distinta (STRAUS; HOWE, 1991; MCCRINDLE; WOLFINGER, 2009; MCQUEEN, 2011).

Atualmente são quatro as gerações que trabalham e convivem simultaneamente: os chamados Baby Boomers (os nascidos entre 1945 e 1965), a geração X (os nascidos entre meados da década de 60 até final dos anos 70), a geração Y (os nascidos na década de 80 até meados dos anos 90), e a geração Z (os nascidos a partir de meados da década de 90). McCrindle e Wolfinger $(2009$, 16) esclarecem que o termo geração designava o espaço de tempo entre o nascimento dos pais e o nascimento dos filhos - até algum tempo atrás, algo em torno de 20 anos, mas que na atualidade, em função das mudanças comportamentais, como o fato dos pais terem filhos cada vez mais tarde, o termo geração refere-se "ao grupo de pessoas nascidas e criadas em um período específico do tempo.”

Apesar de popular, a abordagem sofre uma série de críticas. McQueen (2011) apresenta algumas limitações da "teoria das gerações", entre elas o reconhecimento de que o comportamento humano é complexo e sofre influências de gênero, cultura, nacionalidade, personalidade - entre outros fatores, além do período de nascimento. Ainda, salienta que a teoria deve ser vista como uma abordagem descritiva - e não prescritiva. Ou seja, o excesso de generalizações é visto como um problema e um fator que requer atenção e cuidado na condução de pesquisas no campo.

Seguindo perspectiva descritiva, o instituto de pesquisa IBOPE realizou levantamento do perfil da população, com análise em função das gerações. Entre os resultados, aponta que $68 \%$ de pessoas da geração Y trabalham, 34\% estão cursando o ensino superior, 54\% já saíram da casa dos pais e $31 \%$ são chefes de família. Enquanto da geração Z, 96\% são solteiros, $31 \%$ já estiveram o primeiro trabalho, $84 \%$ estudam e $36 \%$ odeiam fazer qualquer tipo de trabalho doméstico. (IBOPE, 2010)

Quando analisado no contexto das produções acadêmicas, são recorrentes as publicações que trazem a temática das gerações na perspectiva das relações de trabalho (VELOSO; DUTRA; NAKKATA, 2008; PERRONE et al, 2012; CAPPI; ARAUJO, 2015; COMAZZETTO et al, 2016). Entretanto, quando o loco do estudo envolve ambientes 
educacionais de ensino superior, observa-se o tema ainda incipiente no Brasil. Em levantamento realizado em outubro de 2016 na plataforma de pesquisa Scielo e Portal de Periódicos Capes, com o uso dos termos "geração x" ou "geração y" ou "geração z", foram detectados cinco artigos, todos com foco no mercado de trabalho e ambiente organizacional, apontando uma possível lacuna de pesquisa.

Apesar da relevância da abordagem no meio organizacional, é notório que indivíduos, especialmente das gerações $\mathrm{X}, \mathrm{Y}$ e Z, encontram-se em fase de desenvolvimento profissional frequentando instituições de ensino superior. Neste cenário, entende-se que as instituições de ensino precisam conhecer o perfil de seus alunos, visando o desenvolvimento de relações de ensino-aprendizagem mais assertivas. Tal contexto mostra-se especialmente relevante em cursos de Administração de instituições de ensino privadas, haja vista que o curso é o mais numeroso do Brasil (XAVIER, 2012) e, portanto, enfrenta cenário de elevada competitividade. Considerando exposto, a presente pesquisa pretende responder "Como o perfil dos alunos de Administração de uma instituição de ensino privada se relacionam aos estudos das gerações XYZ?". Deste modo, o objetivo geral deste trabalho configura-se em "analisar o perfil dos alunos de Administração de uma instituição de ensino privada à luz das gerações XYZ".

\section{O ESTUDO DAS GERAÇÕES}

Apesar de ser considerada tema atual (MOTTA, 2010), a teoria das gerações remete ao artigo publicado em 1923 por Karl Mannheim, intitulado “The Problem of Generations". Para Pilcher (1994), Mannheim traz um olhar sociológico a temática das gerações, situando os grupos de acordo com os contextos sócio culturais dominantes. Em uma interpretação da obra de Mannheim, a autora afirma que:

Os indivíduos contemporâneos estão internamente estratificados: por sua localização geográfica e cultural; Pela participação real em oposição à potencial nas correntes sociais e intelectuais de seu tempo e lugar; E por suas diferentes respostas a uma situação particular, possibilitando o desenvolvimento de unidades de geração opostas. (Livre tradução de PILCHER, 1993, 483).

Desta forma, o enquadramento às gerações fundamenta-se menos em função de um período no tempo específico e mais em acontecimentos marcantes de um período - como o fim da Segunda Guerra Mundial, por exemplo - determinando o grupo de indivíduos 
caracterizados como baby boomers, na cultura ocidental. (MCCRINDLE; WOLFINGER, 2009)

Posteriormente, Straus e Howe (1991) fundamentaram-se na abordagem sociológica das gerações de Mannheim para analisar e categorizar a população norte-americana. Os autores fazem um recorte geográfico e apresentam quatro grupos principais, determinados a partir de acontecimentos mundiais relevantes, como a Primeira e Segunda Guerra Mundial. O primeiro grupo é denominado Geração G.I. (Governamental Issue, termo vinculado a geração que nasceu durante e após a Primeira Guerra Mundial, entre 1901 e 1924). Esta geração é considerada por Straus e Howe $(1991,26)$ como uma geração cívica/ heroica. "São os solucionadores de problemas racionais da América do século XX, aqueles que sempre souberam fazer grandes coisas". O segundo grupo, chamado de Geração Silenciosa, é formado por nascidos entre 1925 e 1942, que crescem num ambiente sufocado pela crise, tornando-se adultos conformados com os problemas. A Geração Baby Boomers, de nascidos entre 1943 e 1960 (pós segunda guerra mundial) formam o terceiro grupo. Para Straus e Howe (1991) são pessoas idealistas, que crescem como jovens indulgentes após uma crise, cultivam princípios moralistas na meia idade e emergem como visionários na velhice. Denominados de $13^{\text {a }}$ Geração - os atuais Geração X - (nascidos entre 1961 e 1981), são descritos como um padrão reativo à uma geração idealista. Tendem ao esgotamento na juventude, para depois, na fase adulta, adotar uma vida pragmática, conservadora e orientada à família. Para Beckendorff, Moscardo e Pendergast (2010) o trabalho de Straus e Howe (1991), somado ao de Mannheim, Huntley e Fields et al, configuram-se como os principais estudos sobre a teoria das gerações.

Apesar da existência de grupos anteriores à geração de baby boomers, pesquisadores atuais focam análise a partir desta geração, além de incluir as gerações posteriores, denominadas de Y e Z. (DUFFETT, 2017; BECKENDORFF; MOSCARDO; PENDERGAST, 2010; MCCRINDLE; WOLFINGER, 2009). É válido destacar que não se observa, na literatura, uma homogeneidade em relação aos períodos de coorte, embora se constate certa homogeneidade. A Figura 1 ilustra algumas das diferenças e semelhanças observadas. 
Figura 1 Coortes das Gerações

\begin{tabular}{|l|l|l|l|l|}
\hline & Baby boomer & Geração X & Geração Y & Geração Z \\
\hline Straus e Howe (1991) & $1943-60$ & $1961-81^{*}$ & $1982-91^{* *}$ & - \\
\hline Sheahan (2005) & $1946-64$ & $1965-77$ & $1978-94$ & - \\
\hline Kotler e Keller (2006) & $1946-64$ & $1966-77$ & $1977-94$ & $1995-2002$ \\
\hline $\begin{array}{l}\text { Lombardía, Stein e Ramón } \\
(2008)\end{array}$ & $1951-64$ & $1965-83$ & $1984-90$ & - \\
\hline McCrindle e Wolfinger (2009) & $1945-64$ & $1965-79$ & $1980-94$ & $1995-2009$ \\
\hline Ceretta e Froemming (2011) & $1946-64$ & $1965-76$ & $1977-88$ & $1989-2010$ \\
\hline Calliari e Motta (2012) & $1946-64$ & $1965-79$ & $1980-95$ & - \\
\hline Perrone et al (2013) & Anos 60 & $1961-79$ & $1980-90$ & - \\
\hline Comazzetto et al. (2016) & Até 1964 & $1965-77$ & $1978-$ atual & - \\
\hline
\end{tabular}

* Autores denominam esta geração como "Thirteenth Generation" (13 Geração)

** Autores denominam esta geração como "Millennial Generation” (Geração Milênio)

Fonte: Elaborado pelos autores

Importante destacar o trabalho de Motta, Rossi e Schewe (2002) sobre gerações, aplicada à realidade brasileira em comparativo à norte americana. Os autores sugerem seis grupos determinados em função de momentos históricos e econômicos significativos no Brasil, são eles: Era Vargas (1930-45), Pós Guerra (46-64), Otimismo (55-67), Anos de Ferro (68-79), Década Perdida (80-91) e Seja Você Mesmo (1992 em diante). Embora relevante, não foram identificados artigos científicos ou outras produções acadêmicas nacionais sobre gerações tendo como base a categorização proposta pelos autores citados. Em função disto, utiliza-se neste estudo os coortes propostos nas gerações X, Y e Z.

\subsection{GERAÇÃO X}

A geração $\mathrm{X}$ inclui pessoas que nasceram meados da década de 60 até o final dos anos 70, portanto têm, atualmente entre 38 e 50 anos, aproximadamente. Segundo Teixeira (2014, p.3), "os membros da geração X são os filhos dos boomers mais velhos e nasceram em um período de transição e instabilidade financeira". São indivíduos que entram na fase intermediária do ciclo de vida, considerada uma fase de conquista e poder. Portanto, frequentemente assumem cargos gerenciais e de tomada de decisão. "Membros da Geração X são normalmente experts em seus campos de atuação, mas diferem dos baby boomers por verem a liderança de forma cooperativa e o trabalho em equipe como práticas desejáveis no campo de trabalho”.(BECKENDORFF; MOSCARDO; PENDERGAST, 2010, 5).

Para McCrindle e Wolfinger (2009, 9), a Geração X é uma "ponte perfeita entre gerações", uma vez que este grupo adota a ética no trabalho e o foco dos Baby Boomers, 
embora consigam se conectar com facilidade à cultura, visão de mundo e até valores da Geração Y. Uma dificuldade desta geração, apontada por Mattos (2011, p.69), reside em se mostrarem "inseguros quando a situação merece uma socialização de ideias". O autor ainda cita que os profissionais da geração X dão importância ao emprego o que, em alguns casos, afeta qualidade de vida. Estes profissionais possuem uma capacidade de aprendizagem ágil, gerando resultados, e utilizando suas experiências profissionais. Para motivar uma pessoa da geração X sugere-se o desenvolvimento de ambientes de trabalho que promovam a liberdade e autonomia para que o indivíduo possa criar. (TEIXEIRA et al, 2014)

\subsection{GERAÇÃO Y}

Pessoas desta geração nasceram entre o início da década de 80 até meados dos anos 90, ou seja, são indivíduos entre 21 e 37 anos, aproximadamente. Esta geração, de acordo com McCrindle e Wolfinger (2009) é também é conhecida como Geração Millennials ou "Dot.Com Generation" (como termo alusivo à geração da internet).

Assim, as pessoas da geração Y são apontadas como os filhos da tecnologia, por estarem desde pequenos imersos a esse mundo de interatividade e ambiente digital (VELOSO; DUTRA; NAKKATA, 2008; VASCONCELOS, 2010; BORGES, 2015). Para Vasconcelos (2010), a rápida mudança nos meios de comunicação não intimidam os jovens desta geração, face a familiaridade existente com os recursos tecnológicos.

Possuem uma forte ligação com "marcas, amigos, diversão e cultura digital”, além disso, são considerados "confiantes e relaxados, conservadores e a geração mais educada de todas". (BECKENDORFF; MOSCARDO; PENDERGAST, 2010, 6). Diferentemente, McCrindle e Wolfinger $(2009,10)$ os definem como inconstantes, individualistas e egoístas. Para os autores, tal comportamento reflete a realidade dos tempos atuais, em que "os ciclos econômicos chegam e vão, os empregos não são garantidos e os lucros são aparentemente preeminentes - por isso não é um egoísmo inerente, mas uma resposta às realidades corporativas". Corrobora Lombardía, Stein e Ramón (2008) ao exemplificar a abordagem adequada para tratar com indivíduos da Geração Y no ambiente de trabalho.

A primeira conclusão a que se pode chegar em relação ao mercado profissional é a seguinte: não adianta oferecer a esses jovens desafios do tipo "Aqui você vai aprender muito, terá a oportunidade de conhecer diversos departamentos, poderá viajar...”. É um mau começo. A resposta óbvia do jovem Y será: “Olhe, diga o que eu tenho de fazer (objetivo) e não queira 
saber como vou fazer (o procedimento é coisa minha e não agrega valor); respeite minha vida (o que não tem a ver com trabalho: vida são gostos, amigos, estar sempre atualizado etc.) e me informe quanto vou ganhar". (LOMBARDIA; STEIN; RAMÓN, 2008, p.5)

Para Mattos (2011, p.70), as motivações da geração Y englobam "responsabilidade e desafios crescentes, liberdade e flexibilidade para atingir resultados, busca por oportunidades para crescimento contínuo, acesso direto às lideranças com retorno intensivo e sistemático e, ambientes de trabalho mais descontraídos". Especificamente no tocante ao ensino, Toledo, Albuquerque e Magalhães (2012) sugerem que "os alunos dessa geração dão valor para o nível de atualização das informações". Os autores argumentam que as informações precisam ser atuais, "pois, há uma relação com a informação que inclui muitas coisas e de forma mais abrangente (...) querem resultados imediatos".

\subsection{GERAÇÃO Z}

A geração $Z$ engloba jovens nascidos entre meados da década de 90 , sendo o período final incerto - assim, são pessoas com até 20 anos. Duffett (2017) caracteriza o grupo como "screenadicts" ou "screenagers" (do inglês, viciado em tela ou era das telas), pois somente conhecem o mundo com acesso contínuo e instantâneo à internet. Consoante, Cerreta e Froeming $(2011$, p.5) afirmam que os jovens e crianças da geração $Z$ "nunca conceberam o mundo sem computador, chats e telefone celular, e em decorrência disso, são menos deslumbrados que os da Geração Y". O autor cita ainda que "sua maneira de pensar foi influenciada, desde o berço, pelo mundo complexo e veloz que a tecnologia engrenou".

A era da Internet, com informação a qualquer tempo, sobre qualquer assunto, impulsiona o desenvolvimento de nativos digitais "multitarefas", com elevados níveis de criatividade, expressividade e individualidade, conectados a dispositivos mobile entre outros recursos tecnológicos. "Estes jovens consumidores desejam tudo, em todo lugar e instantaneamente. Entretanto, são capazes de filtrar rapidamente mensagens chatas e irrelevantes e manter seu foco em mensagens criativas" (DUFFETT, 2017, p.22). O autor sugere que as pessoas da geração $\mathrm{Z}$ tendem a apresentar comportamento antissocial e individualista, em face da intensa relação com os recursos tecnológicos. 


\section{PERFIL DOS ALUNOS DO CURSO DE ADMINISTRAÇÃO}

A Administração é o curso mais numeroso do Brasil. De acordo com Xavier (2012, p.1), “(...) são cerca de 630.000 alunos e é um dos mais importantes, oferecido por 2.600 estabelecimentos de ensino, segundo dados do CRA - RJ, em 2006".

É no curso de Administração que as competências do profissional são formadas. Além disso, a universidade é muito mais do que um curso - é nesse momento em que os alunos jovens passam da adolescência para a vida adulta, com responsabilidades distintas daquelas vividas no ensino médio, além do que, enquanto estudante universitário, muitas coisas mudam e se aprimoram, como, por exemplo, suas habilidades, atitudes e comportamentos (XAVIER, 2012).

Os estudos desenvolvidos tendo como sujeitos de pesquisa alunos do curso de Administração normalmente retratam o perfil e motivações dos acadêmicos de uma instituição de ensino específica. Em uma instituição de ensino superior do sul do Brasil, por exemplo, Santos (2012) identificou que a maioria dos estudantes pesquisados $(58,7 \%)$ era funcionário de empresa privada, sendo que "o restante dos alunos se dividem em setor público, estagiário, sem vínculo profissional, e um número reduzido de empresários” (SANTOS, 2012, p.11). Para o autor, "a graduação em Administração funciona como um vínculo para a capacitação profissional de pessoas dotadas de perfil empreendedor". Consoante, Coscodai e Arbex (2011, p.4) afirma que "a formação de uma identidade profissional faz parte do processo final de construção da identidade social real. Isso implica na escolha dentre as possíveis identidades disponíveis pela socialização".

Outro estudo realizado com alunos do curso de Administração de uma universidade federal do Rio de Janeiro, Xavier (2012, p.3) pontua que "os estudantes classificam a graduação como demasiadamente generalista, e talvez por isso, sintam-se desorientados ao longo dela, gerando uma desmotivação de seguir a frente à carreira depois de formado". Neste sentido, Xavier $(2005$, p.13) salienta que “a articulação teoria-prática no processo de formação de Administradores deve ser uma condição indispensável”, minimizando possíveis efeitos negativos da formação generalista. Xavier (2012) também afirma que para ingressar no mercado de trabalho, os estudantes "anseiam por líderes que os ajudem a solidificar o caminho a ser seguido, quando, em um primeiro momento, o caminho parece obscuro e sem consonância com a graduação cursada". 
Além dos estudos já citados, Coscodai e Arbex (2011, p.6), a partir de uma pesquisa realizada em instituição de ensino no sul do Brasil, afirma que "a motivação para a escolha feita pelos alunos da IES privada é mais focada na praticidade e comodidade para realizar o curso, com algum destaque para a facilidade financeira (bolsas concedidas)". Já com relação à escolha do curso da Administração, o autor expõe que o mercado de trabalho é o fator principal.

\section{PROCEDIMENTOS METODOLÓGICOS}

A presente pesquisa trata-se de estudo exploratório-descritivo, de abordagem predominantemente quantitativa, mediante realização de pesquisa survey com aplicação de questionário auto-administrado (HAIR JR, 2005) a 152 alunos do curso de Administração de uma faculdade privada, situada em Florianópolis, Santa Catarina. A Faculdade Alfa, objeto de estudo, é considerada uma instituição sólida, com mais de 10 anos de atuação e mantém um Índice Geral de Cursos (IGC) de nota 4,0 (máximo de 5,0). Optou-se por realizar o estudo em uma faculdade privada em face dos desafios mercadológicos enfrentados para captação e manutenção de alunos, o que torna especialmente relevante conhecer o perfil e motivação dos acadêmicos. Neste sentido, a pesquisa apresenta também característica de estudo de caso (YIN, 2005), sendo o "caso" ou fenômeno analisado o perfil e motivações dos acadêmicos de Administração da Faculdade Alfa, à luz das gerações XYZ.

No tocante à operacionalização da pesquisa, sua execução ocorreu em duas fases. A primeira, de caráter qualitativo, envolveu a realização de entrevistas com a coordenação do curso de Administração e três professores que lecionam há mais de cinco anos na instituição. As entrevistas foram conduzidas com o objetivo levantar percepções para auxiliar o desenvolvimento do questionário. A análise interpretativa, combinada à revisão de literatura, resultaram em questionário composto por três partes: (a) Preferências e comportamentos em sala; (b) Comportamento fora de sala e visão de futuro; (c) Perfil demográfico. As escalas foram, em sua maioria, do tipo classificação somada (Likert) de cinco pontos, a exceção das escalas não-métricas do tipo nominal, para identificar o perfil demográfico (HAIR JR, 2005). As gerações foram categorizadas a partir da faixa etária indicada pelo aluno, categorizadas nos seguintes grupos: até 20 anos (Geração Z); de 21 a 25 anos (Geração Y); de 26 a 29 anos (Geração Y); de 30 a 35 anos (Geração Y); de 36 a 40 anos (Geração Y); e mais de 40 anos (Geração X). Dado o número restrito de respondentes classificados como Geração X (4 ao 
total), um novo agrupamento foi realizado, incluindo a faixa etária "36 a 40 anos" como pertencente à Geração X. Tal agrupamento encontra respaldo na categorização indicada por Lombardía, Stein e Ramón (2008).

A fase quantitativa se refere à pesquisa survey, aplicada com os alunos do curso de administração da Faculdade Alfa. De acordo com os dados fornecidos pela instituição, o curso de Administração da Faculdade Alfa possui 185 alunos, rateados em oito fases. Buscou-se realizar uma pesquisa censitária, porém, face a questões de acessibilidade, obteve-se participação de 152 alunos. A amostra alcançada, no entanto, corresponde à margem de erro de $3,4 \%$ e intervalo de confiança de $95 \%$, o que configura níveis de confiança estatística aceitáveis para a pesquisa (HAIR JR, 2005).

Após a coleta, os dados foram tabulados em planilhas Excel e analisados com uso do software de pesquisa SPSS V.23. Foram aplicadas estatísticas descritivas para análise do perfil demográfico e tabulação cruzada com uso de análise de variância (ANOVA) para verificar a relação entre as variáveis comportamentais (preferências em sala, comportamentos em sala, visão de futuro, motivação e comprometimento) e as gerações XYZ.

\section{APRESENTAÇÃO DE RESULTADOS}

Nesta seção são apresentados os dados coletados, iniciando com as informações sobre o perfil demográfico, em seguida, informações sobre preferências e comportamentos em sala de aula, e na sequência, comportamento fora de sala de aula e visões de futuro. Posteriormente são abordadas as motivações e comprometimento dos alunos, bem como o perfil do aluno do curso de Administração da Faculdade Alfa. Ao final, as análises cruzadas abordam as características mapeadas à luz das gerações.

\subsection{PERFIL DEMOGRÁFICO DOS RESPONDENTES}

O perfil demográfico dos alunos do curso de Administração da Faculdade Alfa foi desenvolvido mediante o levantamento das variáveis: gênero, composição familiar, atividades profissionais e idade.

Em relação ao gênero, foi observada uma proporção muito similar de homens e mulheres. Dos 152 respondentes, 52\% são homens, e 48\% são mulheres. Em relação à composição familiar, $67,1 \%$ dos respondentes moram com os pais ou familiares. Outros 18,4\% moram com companheiro/cônjuge/namorado, 8,6\% moram sozinhos, 3,3\% moram 
com a própria família, e 2,6\% moram em república/amigos. Do total de respondentes, 32,2\%, são empregados em empresa privada, 22,4\% fazem estágio, 19,1\% trabalham na empresa da sua família, $13,8 \%$ tem o seu próprio negócio, $11,8 \%$ não exercem nenhuma atividade profissional, 7,9\% são autônomos e 1 respondente é funcionário público. As faixas etárias foram categorizadas com as gerações X, Y e Z, conforme pode ser visualizado na Tabela 1 .

Tabela 1 Idade e Gerações

\begin{tabular}{|c|c|c|c|}
\hline Idade & Freq. Abs. & Freq. Rel. & Gerações \\
\hline Até 20 anos. & 31 & $20,4 \%$ & Geração Z \\
\hline de 21 a 25 anos. & 82 & $53,9 \%$ & Geração Y \\
\hline de 26 a 29 anos. & 20 & $13,2 \%$ & Geração Y \\
\hline de 30 a 35 anos. & 15 & $9,9 \%$ & Geração X \\
\hline de 36 a 40 anos. & 4 & $2,6 \%$ & Geração X \\
\hline Total & 152 & $100,0 \%$ & \\
\hline
\end{tabular}

Fonte: Dados primários, 2017.

Os dados indicam predominância da Geração Y, representando 67,1\% dos alunos, sendo que 53,9\% correspondem a jovens com a idade entre 20 a 25 anos, e 13,2\% são os jovens com a idade entre 26 e 29 anos.

\subsection{PREFERÊNCIAS E COMPORTAMENTOS EM SALA DE AULA}

Com a finalidade de identificar o perfil psicográfico dos alunos do curso de Administração da Faculdade Alfa, os respondentes foram questionados a respeito de suas preferências e comportamento em sala de aula.

Tabela 2 Médias das preferências em sala (geral e por geração XYZ)

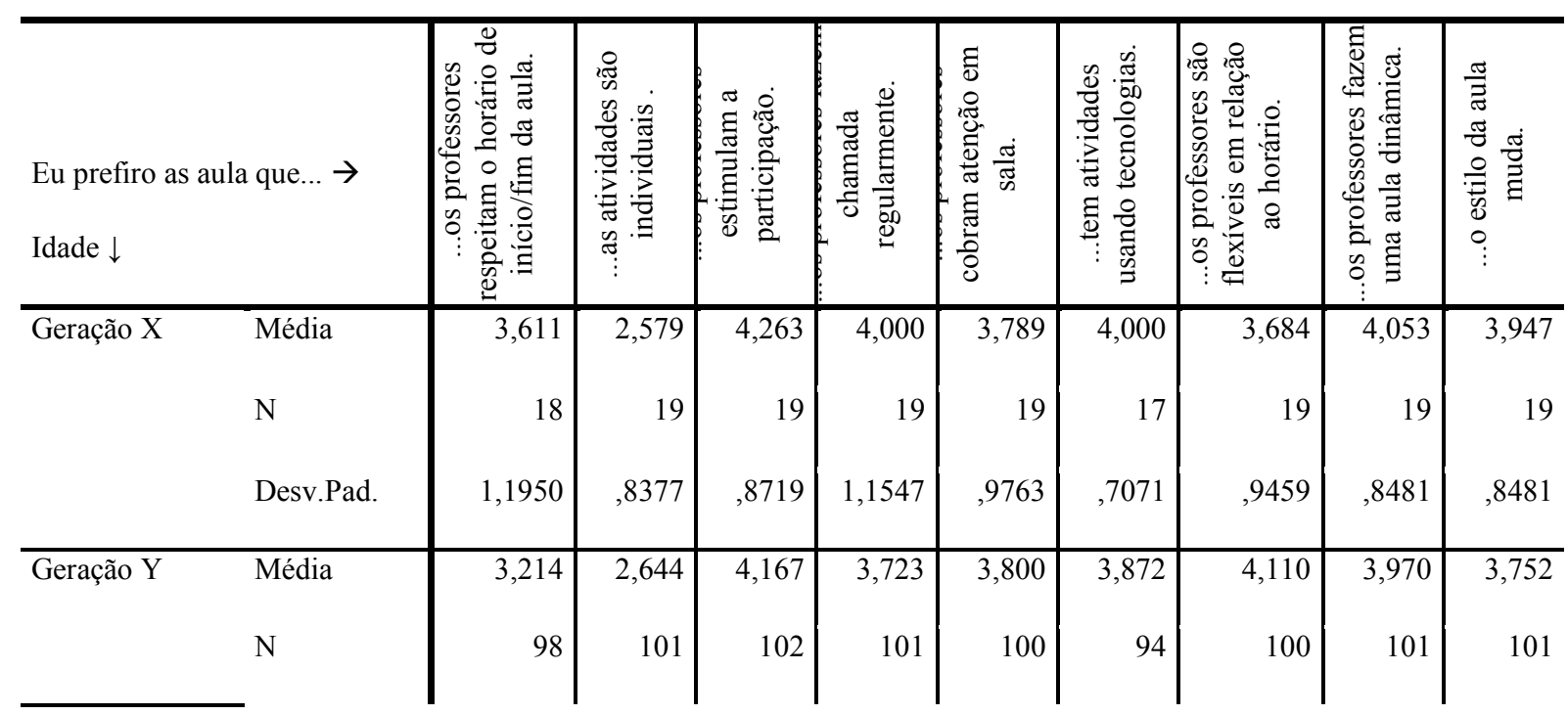




\begin{tabular}{ll|r|r|r|r|r|r|r|r|r}
\hline & Desv.Pad. & 1,0179 & 1,1365 &, 6613 & 1,1499 &, 9847 &, 9186 &, 8633 &, 8770 & 1,1782 \\
\hline Geração Z & Média & 3,167 & 2,548 & 4,194 & 4,226 & 3,448 & 3,800 & 4,000 & 3,806 & 3,900 \\
& $\mathrm{~N}$ & 30 & 31 & 31 & 31 & 29 & 30 & 31 & 31 & 30 \\
& Desv.Pad. &, 7915 & 1,0595 &, 9458 &, 7169 &, 8275 &, 9613 &, 9661 & 1,0139 & 1,0939 \\
\hline Total & Média & 3,253 & 2,616 & 4,184 & 3,861 & 3,730 & 3,872 & 4,033 & 3,947 & 3,807 \\
& $\mathrm{~N}^{*}$ & 146 & 151 & 152 & 151 & 148 & 141 & 150 & 151 & 150 \\
& Desv.Pad. & 1,0021 & 1,0823 &, 7496 & 1,0896 &, 9590 &, 9012 &, 9005 &, 9003 & 1,1215 \\
\hline
\end{tabular}

* Respostas à categoria "sem opinião" não foram computadas, resultando em $\mathrm{N}<152$ (alguns casos)

Fonte: Dados primários, 2017.

$\mathrm{Na}$ escala utilizada para analisar preferências em sala (Tabela 2) as respostas poderiam variar de discordo totalmente (valor $=1$ ) a concordo totalmente (valor=5). Nota-se que as preferências dos alunos dizem respeito ao estímulo à participação $(4,184)$ e flexibilidade em relação ao horário $(4,033)$. Cabe destacar que o curso em questão é ofertado no período noturno e mais de $90 \%$ dos respondentes trabalham ou fazem estágio durante o dia.

Na realização da análise de variância (ANOVA), os resultados apontam níveis de significância elevados, variando de 0,06 a ,902, combinados a índices F baixos (,076 a 1,429), o que sinaliza baixa significância estatística do modelo global de regressão. O resultado já era esperado em função da pouca variação entre as médias obtidas por geração, indicando que as preferências dos alunos em sala de aula não diferem em níveis estatisticamente significativos, quando comparadas à geração XYZ.

Tabela 3 Médias dos comportamentos em sala (geral e por geração XYZ)

\begin{tabular}{|c|c|c|c|c|c|c|c|c|c|c|c|}
\hline \multicolumn{2}{|c|}{ Em sala eu... $\rightarrow$} & 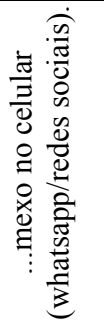 & 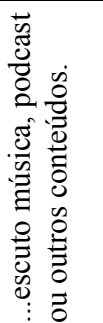 & 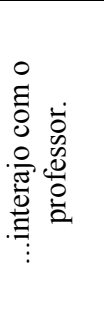 & 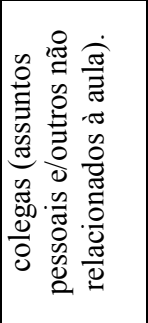 & 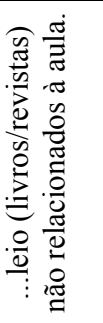 & 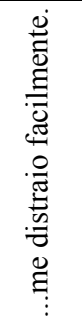 & 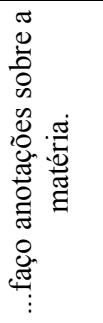 & 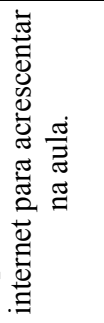 & 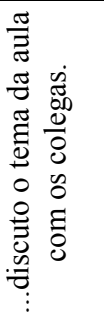 & 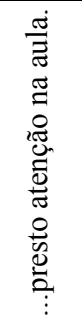 \\
\hline \multirow{3}{*}{$\begin{array}{c}\text { Geração } \\
\text { X }\end{array}$} & Média & 3,053 & 1,211 & 3,842 & 2,421 & 1,895 & 2,632 & 4,000 & 3,211 & 3,579 & 4,263 \\
\hline & $\mathrm{N}$ & 19 & 19 & 19 & 19 & 19 & 19 & 19 & 19 & 19 & 19 \\
\hline & Desv.Pad. & 9703 & 4189 & 6882 & 7685 & 1,0485 & (7609 & 8819 & ,9763 & 9016 & 7335 \\
\hline
\end{tabular}




\begin{tabular}{ll|r|r|r|r|r|r|r|r|r|r}
\hline Geração & Média & 3,706 & 1,176 & 3,412 & 3,020 & 1,725 & 3,333 & 3,627 & 2,891 & 3,078 & 4,069 \\
& $\mathrm{~N}$ & 102 & 102 & 102 & 102 & 102 & 102 & 102 & 101 & 102 & 101 \\
& Desv.Pad. &, 8512 &, 5524 &, 9049 &, 9118 &, 9028 &, 9370 & 1,0042 & 1,0574 &, 7667 &, 5524 \\
\hline $\begin{array}{l}\text { Geração } \\
\mathrm{Z}\end{array}$ & Média & 3,387 & 1,161 & 2,871 & 3,226 & 1,742 & 3,097 & 3,800 & 2,484 & 3,065 & 4,267 \\
& $\mathrm{~N}$ & 31 & 31 & 31 & 31 & 31 & 31 & 30 & 31 & 31 & 30 \\
& Desv.Pad. &, 8823 &, 3739 &, 8462 & 1,0234 &, 9989 & 1,0756 &, 8052 &, 9957 &, 9286 &, 5833 \\
\hline Total & Média & 3,559 & 1,178 & 3,355 & 2,987 & 1,750 & 3,197 & 3,709 & 2,848 & 3,138 & 4,133 \\
& N* & 152 & 152 & 152 & 152 & 152 & 152 & 151 & 151 & 152 & 150 \\
& Desv.Pad. &, 8969 &, 5030 &, 9092 &, 9419 &, 9367 &, 9700 &, 9563 & 1,0504 &, 8303 &, 5870 \\
\hline
\end{tabular}

* Respostas à categoria "sem opinião" não foram computadas, resultando em $\mathrm{N}<152$ (alguns casos) Fonte: Dados primários, 2017.

$\mathrm{Na}$ escala utilizada para analisar comportamentos em sala (Tabela 3) as respostas poderiam ser nunca (valor $=1$ ), raramente (valor=2), às vezes (valor=3), quase sempre (valor=4), sempre (valor=5) ou "sem opinião" (valor não computado). As médias obtidas indicam frequência moderada, com destaque para "presto atenção na aula" $(4,13)$. Os comportamentos menos frequentes, segundo as respostas obtidas, são "escuto música (...)" $(1,17)$ e "leio (livros/revistas)"(1,75).

Tabela 4 ANOVA para "Comportamentos em Sala" Vs. "Gerações"*

\begin{tabular}{|c|c|c|c|c|c|c|}
\hline \multicolumn{2}{|c|}{ Em sala de aula, eu... x Geração XYZ } & $\begin{array}{l}\text { Soma dos } \\
\text { Quadrados }\end{array}$ & $\mathrm{gl}$ & $\begin{array}{l}\text { Quadrado } \\
\text { Médio }\end{array}$ & $\mathrm{F}$ & Sig. \\
\hline \multirow{3}{*}{$\begin{array}{l}\text {...mexo no celular } \\
\text { (whatsapp/redes sociais) * } \\
\text { Geração XYZ }\end{array}$} & Entre Grupos $\quad$ (Combinado) & 7,988 & 2 & 3,994 & 5,244 &, 006 \\
\hline & Nos grupos & 113,479 & 149 & ,762 & & \\
\hline & Total & 121,467 & 151 & & & \\
\hline \multirow{3}{*}{$\begin{array}{l}\text {...interajo com o professor. * } \\
\text { Geração XYZ }\end{array}$} & Entre Grupos $\quad$ (Combinado) & 12,100 & 2 & 6,050 & 7,997 & 001 \\
\hline & Nos grupos & 112,716 & 149 & ,756 & & \\
\hline & Total & 124,816 & 151 & & & \\
\hline \multirow{2}{*}{$\begin{array}{l}\text {...converso com os colegas } \\
\text { (assuntos não relacionados à } \\
\text { aula). * Geração XYZ }\end{array}$} & Entre Grupos $\quad$ (Combinado) & 7,962 & 2 & 3,981 & 4,707 &, 010 \\
\hline & Nos grupos & 126,012 & 149 & ,846 & & \\
\hline
\end{tabular}




\begin{tabular}{|c|c|c|c|c|c|c|}
\hline & Total & 133,974 & 151 & & & \\
\hline \multirow{3}{*}{$\begin{array}{l}\text {...me distraio facilmente. * } \\
\text { Geração XYZ }\end{array}$} & Entre Grupos $\quad$ (Combinado) & 8,282 & 2 & 4,141 & 4,611 & 011 \\
\hline & Nos grupos & 133,797 & 149 & 898 & & \\
\hline & Total & 142,079 & 151 & & & \\
\hline \multirow{3}{*}{$\begin{array}{l}\text {...procuro conteúdo na internet } \\
\text { para acrescentar na aula. * } \\
\text { Geração XYZ }\end{array}$} & Entre Grupos $\quad$ (Combinado) & 6,795 & 2 & 3,397 & 3,168 &, 045 \\
\hline & Nos grupos & 158,702 & 148 & 1,072 & & \\
\hline & Total & 165,497 & 150 & & & \\
\hline \multirow{3}{*}{$\begin{array}{l}\text {... discuto o tema da aula com } \\
\text { os colegas. * Geração XYZ }\end{array}$} & Entre Grupos (Combinado) & 4,224 & 2 & 2,112 & 3,151 & 046 \\
\hline & Nos grupos & 99,875 & 149 & 670 & & \\
\hline & Total & 104,099 & 151 & & & \\
\hline
\end{tabular}

* Somente correlações com signif. $<0,05$

Fonte: Dados primários, 2017.

Diferentemente do observado em relação às preferências em sala, a análise de variância apresentada na Tabela 5 sugere que algumas variáveis comportamentais se modificam conforme as alterações observadas nas gerações XYZ. Das relações pontuadas, a mais significativa é "interajo com professor" (Soma dos quadrados de regressão 12,100; signif.,001). Ao analisar as médias, observa-se comportamento da geração Z diferente dos demais, com menor intensidade de interação. Tal situação pode decorrer do pouco tempo dos alunos no ambiente acadêmico e da postura mais centrada nas demandas individuais, característica mencionada por Duffett (2017).

Destaca-se também a variável "mexo no celular" (Soma dos quadrados de regressão 7,98; signif.,006). Nesta, a média da geração $X$ tem comportamento ligeiramente distinto das demais, apresentando menor intensidade. Aliás, nos demais casos observados, as médias diferenciadas pertencem à geração X (ver Tabela 3, destaques em azul) e relacionam-se a um perfil que se distrai e conversa em sala em intensidade inferior aos demais, embora discuta temáticas da aula e procure conteúdos na Internet relacionados à aula em frequência maior do que nas gerações $\mathrm{Y}$ e Z. Os dados indicam certa relação com alguns pontos de perfil mencionados na literatura, tais como foco e responsabilidade (MCCRINDLE e WOLFINGER, 2009). 


\subsection{COMPROMETIMENTO, MOTIVAÇÃO E VISÃO DE FUTURO}

Além do comportamento e preferências em sala de aula, buscou-se identificar os níveis de comprometimento e motivação do acadêmico, bem como suas perspectivas em relação ao futuro.

Tabela 5 Comprometimento e Motivação

\begin{tabular}{c|c|c|c|c|c|c|c|c|c}
\hline & \multicolumn{4}{|c|}{ Geração X } & \multicolumn{3}{c|}{ Geração Y } & \multicolumn{3}{c}{ Geração Z } \\
\cline { 2 - 11 } & Méd. & N & DP & Méd. & N & DP & Méd. & N & DP \\
\hline Comprometimento & 4,00 & 19 &, 7454 & 3,21 & 102 &, 7705 & 3,48 & 31 &, 7946 \\
\hline Motivação & 4,00 & 19 & 1,054 & 3,85 & 102 &, 7366 & 4,00 & 31 &, 7953 \\
\hline
\end{tabular}

Fonte: Dados primários, 2017.

Para mensurar o comprometimento questionou-se ao aluno "Como avalia seu comprometimento em relação aos estudos?" e, para motivação "Como avalia sua motivação em relação ao curso de Administração da Faculdade ALFA?”. Ambas questões acompanhavam escala intervalar, em que o respondente poderia escolher de um a cinco, sendo um "nada comprometido" e "nada motivado (não gosto de estar aqui); e cinco "muito comprometido" e "muito motivado (gosto muito de estar aqui)". Os dados revelam maior comprometimento de respondentes da geração X em relação às demais; e menor motivação de respondentes da geração $\mathrm{Y}$, em relação às demais.

Tabela 6 ANOVA para Comprometimento e Motivação Vs. Gerações XYZ

\begin{tabular}{|c|c|c|c|c|c|c|c|}
\hline & & & $\begin{array}{c}\text { Soma dos } \\
\text { Quadrados }\end{array}$ & $\mathrm{gl}$ & $\begin{array}{l}\text { Quadrad } \\
\text { o Médio }\end{array}$ & $\mathrm{F}$ & Sig. \\
\hline \multirow{3}{*}{$\begin{array}{l}\text { Comprometiment } \\
\text { o Vs. Gerações } \\
\text { XYZ }\end{array}$} & Entre Grupos & (Combinado) & 7,639 & 2 & 3,820 & 6,489 &, 002 \\
\hline & Nos grupos & & 87,703 & 149 &, 589 & & \\
\hline & Total & & 95,342 & 151 & & & \\
\hline \multirow{3}{*}{$\begin{array}{l}\text { Motivação Vs. } \\
\text { Geraçôes XYZ }\end{array}$} & Entre Grupos & (Combinado) &, 726 & 2 & ,363 & ,570 &, 567 \\
\hline & Nos grupos & & 94,794 & 149 & ,636 & & \\
\hline & Total & & 95,520 & 151 & & & \\
\hline
\end{tabular}

Fonte: Dados primários, 2017.

A Análise de Variância (ANOVA) indica que as médias obtidas sobre o nível de motivação não variam em função das Gerações XYZ. Situação distinta quando se trata da variável comprometimento. Neste caso, embora o índice F seja baixo, a significância é forte, validando a informação. A soma dos quadrados de regressão $(7,639)$ indica o quanto da variação no "comprometimento" é explicada pelas gerações XYZ. Ao dividir este resultado 
pela soma total de quadrados, observa-se que a variável gerações XYZ responde em 19,41\% as variações no "comprometimento".

\subsubsection{Visão de futuro}

Considerando a importância da atuação profissional e inserção no mercado de trabalho para a motivação do aluno de Administração (XAVIER, 2012; COSCODAI e ARBEX, 2011), buscou-se identificar os interesses dos acadêmicos em relação ao futuro. A Tabela 7 apresenta as médias obtidas, segregadas por geração e no total.

Tabela 7 Médias da visão de futuro (geral e por geração XYZ)

\begin{tabular}{|c|c|c|c|c|c|c|c|c|c|}
\hline \multicolumn{2}{|c|}{$\begin{array}{l}\text { No futuro, eu quero/desejo... } \\
\text { Idade }\end{array}$} & 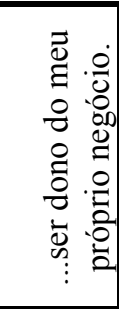 & 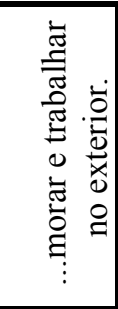 & 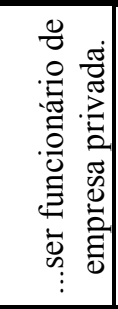 & 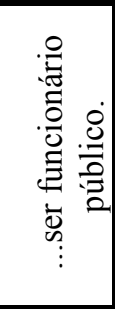 & 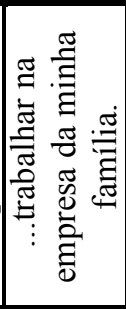 & 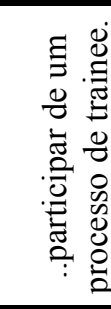 & 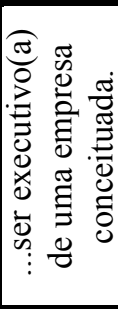 & 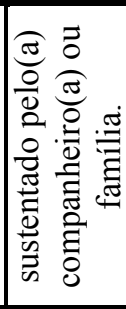 \\
\hline \multirow[t]{3}{*}{ Geração X } & Média & 3,947 & 3,000 & 2,895 & 2,737 & 1,833 & 2,579 & 3,158 & 1,176 \\
\hline & $\mathrm{N}$ & 19 & 19 & 19 & 19 & 18 & 19 & 19 & 17 \\
\hline & & 1,3934 & 1,2472 & 1,1496 & 1,2842 & 1,0981 & 1,3464 & 1,6419 & ,7276 \\
\hline \multirow[t]{3}{*}{ Geração Y } & Média & 4,235 & 3,663 & 2,657 & 2,703 & 2,532 & 2,921 & 3,500 & 1,298 \\
\hline & $\mathrm{N}$ & 102 & 101 & 102 & 101 & 94 & 101 & 102 & 94 \\
\hline & & 1,1006 & 1,1338 & 1,1815 & 1,3896 & 1,3417 & 1,1462 & 1,1920 & -7596 \\
\hline \multirow[t]{3}{*}{ Geração Z } & Média & 3,806 & 3,613 & 3,258 & 2,742 & 3,233 & 2,800 & 3,742 & 1,226 \\
\hline & $\mathrm{N}$ & 31 & 31 & 31 & 31 & 30 & 30 & 31 & 31 \\
\hline & Desv.Pad. & 1,2225 & 1,2021 & 1,2374 & 1,2902 & 1,3047 & , 9248 & -9298 & ,6688 \\
\hline \multirow[t]{3}{*}{ Total } & Média & 4,112 & 3,570 & 2,809 & 2,715 & 2,592 & 2,853 & 3,507 & 1,268 \\
\hline & $\mathrm{N}^{*}$ & 152 & 151 & 152 & 151 & 142 & 150 & 152 & 142 \\
\hline & Desv.Pad. & 1,1711 & 1,1748 & 1,2056 & 1,3485 & 1,3587 & 1,1315 & 1,2125 &, 7334 \\
\hline
\end{tabular}

* Respostas à categoria "sem opinião" não foram computadas, resultando em $\mathrm{N}<152$ (alguns casos) Fonte: Dados primários, 2017.

A escala utilizada nesta questão foi de classificação somada (Likert) de cinco pontos, variado de "discordo totalmente" (valor=1) a "concordo totalmente (valor=5), possibilitando ao respondente não opinar - escala não forçada (HAIR JR, 2005). Os resultados obtidos indicam maior valor de média à variável “desejo ser dono de meu próprio negócio" $(4,112)$, o que revela interesse pelo empreendedorismo, particularmente mais forte entre os respondentes da Geração Y, consoante às características pontuadas por Mattos (2011). Embora o autor tenha enfatizado um ambiente empresarial, tais características (responsabilidade, desafios, liberdade e flexibilidade para atingir resultados) são também associadas à dinâmica empreendedora (DEGEN, 2009). Contrariamente, a variável “desejo não ter trabalho (ser 
sustentado por companheiro(a) ou pela família)" obteve menor valor de média geral $(1,268)$, o que indica uma situação futura não almejada entre os respondentes.

Tabela 4 ANOVA para "Visão de futuro" Vs. "Gerações"*

\begin{tabular}{|c|c|c|c|c|c|c|}
\hline \multicolumn{2}{|c|}{ No futuro, eu quero/desejo... } & $\begin{array}{l}\text { Soma dos } \\
\text { Quadrados } \\
\end{array}$ & $\mathrm{gl}$ & $\begin{array}{l}\text { Quadrad } \\
\text { o Médio } \\
\end{array}$ & $\mathrm{F}$ & Sig. \\
\hline \multirow{3}{*}{$\begin{array}{l}\text {...ser funcionário } \\
\text { de empresa } \\
\text { privada. * } \\
\text { Gerações XYZ }\end{array}$} & (Combinado) & 8,752 & 2 & 4,376 & 3,094 & ,048 \\
\hline & Nos grupos & 210,715 & 149 & 1,414 & & \\
\hline & Total & 219,467 & 151 & & & \\
\hline \multirow{3}{*}{$\begin{array}{l}\text {...trabalhar na } \\
\text { empresa da minha } \\
\text { família. * Gerações } \\
\text { XYZ }\end{array}$} & $\begin{array}{ll}\text { Entre } & \text { (Combinado) } \\
\text { Grupos } & \\
\end{array}$ & 23,039 & 2 & 11,519 & 6,748 & ,002 \\
\hline & Nos grupos & 237,271 & 139 & 1,707 & & \\
\hline & Total & 260,310 & 141 & & & \\
\hline
\end{tabular}

* Somente correlações com signif. $<0,05$

Fonte: Dados primários, 2017.

A comparação entre as variáveis mediante análise de variância indica correlação significativa em apenas duas situações: "trabalhar na empresa da família" e "ser funcionário de empresa privada". Ou seja, a variação de respostas nestes dois casos tem relação com as gerações XYZ. A correlação é mais forte na variável "trabalhar na empresa da família" (soma dos quadrados de regressão 23,03; signif..,002). Neste caso, a variação na visão de futuro profissional é explicada em 8,85\% pelas gerações XYZ. Na Tabela 7 é possível verificar que indivíduos da geração $\mathrm{X}$ concordam em menor grau com esta visão de futuro, se comparado aos demais.

\section{DISCUSSÃO DE RESULTADOS}

Embora as análises de variância realizadas tenham apontado apenas algumas correlações significativas, a análise das médias permite uma observação mais detalhada por geração, sendo possível observar semelhanças e diferenças entre as características apontadas na literatura e os dados identificados na pesquisa.

Beckendorff, Moscardo e Pendergast (2010).indicam, por exemplo, que a Geração X é formada por pessoas responsáveis, com foco no trabalho e que apreciam a liderança cooperativa e o trabalho em equipe. $\mathrm{Na}$ análise das preferências e comportamentos em sala, as médias mais altas da geração $\mathrm{X}$ - comparativamente às demais gerações - revelam interesse por aulas dinâmicas $(4,05)$, pela procura conteúdo na internet para acrescentar nas aulas $(3,21)$ 
- postura colaborativa; e média mais baixa para conversas paralelas $(2,42)$ - postura responsável.

Entretanto, a afirmação de Mattos (2011) a dificuldade para socialização de ideias presente na literatura - não aparenta estar presente nos respondentes da geração $X$ desta pesquisa, haja vista que as maiores médias (entre as gerações) foram observadas neste grupo em relação à variáveis como preferência pelo estímulo à participação $(4,26)$, e comportamentos de interação com o professor $(3,84)$ e com os colegas, ao "discutir tema de aula" $(3,57)$.

Em relação aos respondentes da Geração Y, observou-se preferências a situações mais brandas no contexto de sala de aula, como o controle de frequência mais flexível (maior média: 4,11) e menor média em relação à preferência pela cobrança regular de frequência $(3,73)$. Os dados corroboram o exposto por Mattos (2011), ao afirmar que as motivações desta geração englobam flexibilidade para atingir resultados. Tal situação também é compatível com o interesse em ser dono do próprio negócio, com a maior média entre as demais gerações $(4,23)$.

Outra situação observada na pesquisa referente aos respondentes da Geração Y diz respeito à distração. É neste grupo que se observa as maiores médias para comportamentos como "mexo no celular" $(3,70)$ e "me distraio em sala" $(3,33)$, bem como as menores para "faço anotações em sala" $(3,62)$ e presto atenção $(4,06)$ - quando comparados às demais gerações. Igualmente, são os que se consideram menos comprometidos $(3,21)$ e menos motivados $(3,85)$, comparando às demais gerações. Os autores apontam a geração Y como "filhos da tecnologia", imersos desde cedo no ambiente digital (VELOSO; DUTRA; NAKKATA, 2008; VASCONCELOS et al, 2010), embora não seja possível afirmar, uma hipótese para explicar a distração neste grupo pode residir na relação negativa entre os estímulos tecnológicos e a capacidade de foco e concentração.

Os respondentes da Geração Z, neste estudo, revelam preferências, comportamentos e visão de futuro difusos. Por exemplo, comparativamente às demais gerações, eles apresentam a menor média em relação à preferência por professores que respeitam o horário de início/fim da aula $(3,16)$, mas apresentam a maior média por preferência de realização regular de chamada (cobrança de frequência) $(4,22)$. Também apresentam a maior média em relação à prática de conversa paralela sobre assuntos diversos $(3,22)$, revelando maior distração do que 
os demais - entretanto apresentam também a maior média para "presto atenção em sala" $(4,26)$.

Outra curiosidade diz respeito à relação com a tecnologia. Comparativamente aos demais, os respondentes da geração $Z$ apresentam menores médias em relação à preferência pelo uso da tecnologia em sala $(3,80)$ e ao comportamento de procurar conteúdo na Internet para contribuir em sala $(2,48)$. Tal situação guarda relação com o exposto por Ferreira (2014) ao afirmar que este grupo é intensamente familiarizado com a tecnologia e, por não conhecerem o mundo pré digital, são menos "deslumbrados" que os indivíduos da Geração Y. (CERETTA; FROEMMING, 2011).

Em relação ao futuro, mostram-se os mais interessados em serem um executivo de grande empresa $(3,74)$, comparativamente aos demais. Também revelam interesse pelo empreendedorismo $(3,80)$, embora em menor grau que o observado nas outras gerações.

\section{CONCLUSÃO}

Com popularidade, especialmente no campo dos estudos motivacionais entre os colaboradores, a abordagem das gerações $\mathrm{X}, \mathrm{Y}$ e $\mathrm{Z}$ busca analisar o perfil das pessoas de acordo com o período de nascimento. Considerando o ambiente competitivo entre as instituições de ensino privadas, especialmente no campo da Administração, se faz necessário conhecer e compreender o perfil do acadêmico. Diante deste cenário, o objetivo do presente trabalho foi analisar o perfil dos acadêmicos de Administração da Faculdade Alfa, à luz das gerações XYZ. Para tanto, foi feito realizada pesquisa survey com 152 alunos (margem de erro de 3,4\% e intervalo de confiança de 95\%) mediante aplicação de questionários de autopreenchimento.

Os dados coletados na pesquisa, bem como as análises estatísticas realizadas, revelaram a influência das gerações em algumas situações específicas, em nível baixo a moderado - o que sinaliza cuidado ao tratar do tema "Geração XYZ", evitando a generalização e o uso indevido dos termos. Tais resultados corroboram os apontamentos de McQueen (2011) ao tratar das limitações da abordagem das gerações, lembrando que o estudo é útil quando adota uma perspectiva mais descritiva do que prescritiva, pois o comportamento humano é complexo e não pode ser determinado única e exclusivamente pelo período de nascimento. Neste sentido, buscou-se a análise do comportamento das médias por gerações, permitindo tecer algumas reflexões sobre os grupos. 
As maiores diferenças observadas são em relação à Geração $X$, comparativamente as demais, revelando um perfil comprometido e engajado no tocante ao comportamento em sala, que se reflete também em médias altas de comprometimento e motivação. Em relação aos respondentes da Geração Y, observou-se um perfil que aprecia um ambiente mais flexível em relação às cobranças e regras, entretanto, apresentam maior tendência à distração do que os demais. No tocante à Geração Z, observou-se um perfil difuso, com preferências por vezes antagônicas. E, apesar de serem os "nativos digitais", os respondentes desta categoria não são os que manifestam maior interesse pelo uso da tecnologia em sala.

Em que pese sua natureza de estudo de caso, impedindo generalizações ao campo (YIN, 2005), os resultados desta pesquisa podem servir para fornecer insights a docentes e coordenadores de curso, sobre o perfil e motivações dos discentes. Preferências como “estímulo à participação" $(4,18)$, "aula dinâmica" $(3,94)$ e "com uso de tecnologias"( 3,87$)$ reforçam a proposta de metodologias mais ativas de ensino, superando o formato tradicional de aula expositiva. Fato que é especialmente relevante se for levado em consideração a tendência à distração $(3,19)$, com uso do celular $(3,55)$. Em estudo conduzido por Sobrinho, Pinto e Desidério (2014, p.15) sobre as percepções dos docentes em relação às mudanças no comportamento dos discentes, os autores apontam a existência de um "mundo voltado às tecnologias de informação e comunicação, com intensa penetração tecnológica no cotidiano social", criando um cidadão online que, em sala de aula, também espera encontrar um reflexo desta realidade "digital" e interativa.

Sugere-se, para pesquisas futuras, a realização de estudos de abordagem qualitativa com bases nas gerações, tendo os alunos como sujeitos de pesquisa. A análise de narrativas pode ser particularmente interessante neste caso, permitindo novas reflexões sobre características apontadas na literatura e sobre o papel do professor em sala de aula.

\subsection{LIMITAÇÕES DA PESQUISA}

Esta pesquisa não levou em consideração outras variáveis demográficas além da idade (categorizada nas gerações), embora se reconheça a influência de outros elementos, tais como gênero, cultura, contexto familiar, personalidade, etc. - no comportamento, preferências, motivações e visão de futuro dos discentes. Importante destacar também que, por apresentar caráter quantitativo, é possível que posicionamentos e percepções dos discentes, manifestos na pesquisa, não reflitam em sua plenitude suas reais intenções e comportamentos. Ainda, o 
universo de aplicação da pesquisa não permite a generalização dos dados a outras instituições de ensino, cujo contexto moldado pela natureza da instituição (se pública ou privada), região, porte da instituição, entre outras variáveis, podem interferir igualmente no perfil discente da instituição.

\section{REFERÊNCIAS}

BECKENDORFF, P.MOSCARDO, G. PENDERGAST, D. Tourism and Generation Y. Oxfordshire: CABI International, 2010.

CALLIARI, M; MOTTA, A. Código Y: decifrando a geração que está mudando nosso país. São Paulo: Évora, 2012.

CAPPI, M. N; ARAUJO, B. F. B. Satisfação no Trabalho, Comprometimento Organizacional e Intenção de Sair: um estudo entre as Gerações X e Y. REAd. Rev. eletrôn. adm. [online]. 2015, v.21, n.3. Disponível em:

http://www.scielo.br/scielo.php?script=sci arttext\&pid=S1413-

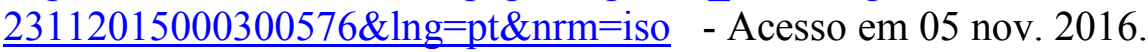

CERETTA, S. B; FROEMMING, L. M. Geração Z: Compreendendo os Hábitos de Consumo da Geração Emergente. Revista Eletrônica do Mestrado Profissional em Administração da Universidade Potigua. Ano III, n. 2 - abr./set, 2011.

COMAZZETTO, L. R. et al . A Geração Y no Mercado de Trabalho: um Estudo Comparativo entre Gerações. Psicol. cienc. prof., Brasília , v. 36, n. 1, p. 145-157, mar. 2016.

COSCODAI, N; ARBEX, M. Como estudantes de administração enxergam o próprio curso? Um estudo com estudantes de graduação de uma instituição pública e de uma instituição privada na região de Londrina/PR. In: VIII Congresso Virtual Brasileiro de Administração -

CONVIBRA, 2011. Anais... CONVIBRA, 2011. Disponível em:

http://www.convibra.com.br/upload/paper/adm/adm_2486.pdf Acesso em 02 out. 2016.

DEGEN, R. O empreendedor: empreender como opção de carreira. São Paulo: Pearson Prentice Hall, 2009.

DUFFETT, R. G. Influence of social media marketing communications on young consumers' attitudes. Young Consumers, V. 18 Issue: 1, 2017.

HAIR JR, J. F; BABIN, B; MONEY, A; SAMOUEL, P. Fundamentos de métodos de pesquisa em administração. Porto Alegre: Bookman, 2005.

IBOPE. Gerações Y e Z: Juventude Digital. IBOPE MÍDIA, 2010. Disponível em:

http://www4.ibope.com.br/download/geracoes $\% 20$ y_e z divulgacao.pdf Acesso em 02 out. 2016. 
KOTLER, P. KELLER, D. Administração de Marketing. 12 ${ }^{\mathrm{a}}$ Ed. São Paulo: Pearson Prentice Hall, 2006.

LOMBARDÍA, P. G., STEIN, G., RAMÓN, J. Quem é a Geração Y? HSM Management, v. 7, n.3 2008. Disponível em http://ftp-acd.puccampinas.edu.br/pub/paaa/TEXTOS/PAAA3/Geracao\%20Y.pdf Acesso em 09 out. 2016.

MATTOS,C. et al. Os desafios na transição da geração X para a Y na Empresa Dori LTDA. Revista Científica do Unisalesiano - LINS - SP, ano 2, n.4, jul/dez de 2011.

MCCRINDLE, M. WOLFINGER, E. The ABC of XYZ: understanding the global generations. Sydney: University of New South Wales Press Ltd., 2009.

MCQUEEN, M. A guide to understanding \& connecting with generation Y. Garden City: Morgan James Publishing, 2011.

MOTTA, A. A atualidade do conceito de gerações na pesquisa sobre envelhecimento. Sociedade e Estado. v.25 n.2 Brasília. Maio/agosto, 2010.

MOTTA, P; ROSSI, M; SCHEWE, C. Generational marketing: exploring cohort-programmed values and their implications on cross-cultural variations in consumer behavior between Brazil and United States. Revista Portuguesa de Marketing, ano 6, n.12, p.11-21, 2002.

PERRONE, C. M., ENGELMAN, S., SANTOS, A. P., SOBROSA, G. M. A percepção das organizações pela Geração Y. Revista de Administração da Universidade Federal de Santa Maria. v.6, n.3, 2012.

PILCHER, J. Mannheim's sociology of generations: an undervalued legacy. British Journal of Sociology. v.45, n.3, 1994.

SANTOS, L; FLORES, A. O perfil empreendedor no ensino superior: o caso dos alunos do curso de graduação em administração em uma cidade do sul do país. In: XXIII Encontro da Associação Nacional dos Cursos de Graduação em Administração - ENANGRAD, 2012, São Paulo. Anais...São Paulo: ANPAD, 2012. Disponível em:

http://xxiiienangrad.enangrad.org.br/anaisenangrad/ resources/media/artigos/egc/11.pdf Acesso em 02 out. 2016.

SOBRINHO, C. A. C; PINTO, I. M. B. S; DESIDÉRIO, P. H. M. Gerações discentes: como era, como está e como será: um olhar a partir da percepção de docentes do curso de administração. IN: XVII SEMINÁRIOS EM ADMINISTRAÇÃO - SEMEAD, 2014, São Paulo. Anais...São Paulo: FEA-USP, 2014. Disponível em http://sistema.semead.com.br/17semead/resultado/trabalhosPDF/840.pdf - Acesso em 20 out. 2016.

STRAUS, W; HOWE, N. The Cycle of Generations. American Demographics, Vol. 13, No. 4, 1991.

SHEAHAN, P. Generation Y: thriving (and surviving) with Generation Y at work. Melbourne:Hardie Grant Books, 2005. 
TEIXEIRA, A. PETUCO, C. GAMARRA, L. KUHSLER, C. TEIXEIRA, R. KLEIN, A. O Sentido do Trabalho: uma análise à luz das Gerações X e Y. Diálogo. 2014. Canoas, n. 25, abr.

TOLEDO, P. B. F.; ALBUQUERQUE, R. A. F.; MAGALHÃES, A. R. O. Comportamento da geração $Z$ e a influência nas atitudes dos professores. In: SIMPÓSIO DE EXCELÊNCIA E GESTÃO EM TECNOLOGIA - SEGeT, 2012, Resende. Anais... Resende: AEDB, 2012.

VASCONCELOS, K. MERHI, D. GOULART, V. SILVA, A. A Geração Y e Suas Âncoras de Carreira. Revista Gestão.Org. . v. 8, n.2. Mai/Ago, 2010.

VELOSO, E. F. R., DUTRA, J. S., NAKATA, L. E. Percepção sobre carreiras inteligentes: diferenças entre as gerações $\mathrm{Y}, \mathrm{X}$ e baby boomers. In XXXII ENCONTRO DA ASSOCIAÇÃO NACIONAL DE PÓS-GRADAÇÃO E PESQUISA EM ADMINISTRAÇÃO - EnANPAD, 2008, Rio de Janeiro. Anais...Rio de Janeiro: ANPAD, 2008.

XAVIER, A. et al. O perfil do Graduando em Administração: Comparando Amostrar de uma Universidade Federal do Rio de Janeiro. In: SIMPÓSIO DE EXCELÊNCIA E GESTÃO EM TECNOLOGIA - SEGeT, 2012, Resende. Anais... Resende: AEDB, 2012.

XAVIER, V; BOAS, A. Perfil do Aluno de Administração de Empresas como Instrumento de Melhoria da Qualidade do Ensino: um estudo de caso. In: V COLOQUIO

INTERNACIONAL SOBRE GESTIÓN UNIVERSITARIA EN AMÉRICA DEL SUR, 2005, Mar del Plata. Anais... Mar del Plata: UNMdP, 2005. Disponível em:

https://repositorio.ufsc.br/xmlui/bitstream/handle/123456789/97152/VOLNEI\%20E\%20ANA $\% 20 \% 20$ ALICE.pdf? sequence $=3 \&$ isAllowed=y Acesso em 02 out. 2016.

YIN, Robert K. Estudo de caso: planejamento e métodos. 3. ed. Porto Alegre: Bookman, 2005. 